\title{
A comparison between tracer gas and aerosol particles distribution indoors: The impact of ventilation rate, interaction of airflows, and presence of objects
}

\author{
Bivolarova, Mariya Petrova; Ondráek, Jakub; Melikov, Arsen Krikor; Ždímal, Vladimír
}

Published in:

Indoor Air

Link to article, DOI:

10.1111/ina.12388

Publication date:

2017

Document Version

Peer reviewed version

Link back to DTU Orbit

Citation (APA):

Bivolarova, M. P., Ondráek, J., Melikov, A. K., \& Ždímal, V. (2017). A comparison between tracer gas and aerosol particles distribution indoors: The impact of ventilation rate, interaction of airflows, and presence of objects. Indoor Air, 27(6), 1201-1212. https://doi.org/10.1111/ina.12388

\section{General rights}

Copyright and moral rights for the publications made accessible in the public portal are retained by the authors and/or other copyright owners and it is a condition of accessing publications that users recognise and abide by the legal requirements associated with these rights.

- Users may download and print one copy of any publication from the public portal for the purpose of private study or research.

- You may not further distribute the material or use it for any profit-making activity or commercial gain

- You may freely distribute the URL identifying the publication in the public portal 


\title{
A comparison between tracer gas and aerosol particles distribution indoors: the impact of ventilation rate, interaction of airflows, and presence of objects
}

\begin{abstract}
The study investigated the separate and combined effects of ventilation rate, free convection flow produced by a thermal manikin, and the presence of objects on the distribution of tracer gas and particles in indoor air. The concentration of aerosol particles and tracer gas was measured in a test room with mixing ventilation. Three layouts were arranged: an empty room, an office room with an occupant sitting in front of a table, and a single-bed hospital room. The room occupant was simulated by a thermal manikin. Monodisperse particles of three sizes $(0.07,0.7$, and $3.5 \mu \mathrm{m})$ and nitrous oxide tracer gas were generated simultaneously at the same location in the room. The particles and gas concentrations were measured in the bulk room air, in the breathing zone of the manikin, and in the exhaust air. Within the breathing zone of the sitting occupant, the tracer gas emerged as reliable predictor for the exposure to all different-sized test particles. A change in the ventilation rate did not affect the difference in concentration distribution between tracer gas and larger particle sizes. Increasing the room surface area did not influence the similarity in the dispersion of the aerosol particles and the tracer gas.
\end{abstract}

Key words: Tracer gas; Particles; Room air distribution; Transport behaviour; Exposure; Thermal Manikin;

\section{Practical Implications}

The results of this study will contribute to a better understanding of the relationship between the transport behaviour of gas and particles. Such knowledge is important for the realistic prediction of aerosol particles distribution in ventilated rooms when using tracer gas techniques. The data can be used to validate CFD models for the evaluation of the distribution of pollutant concentrations and airflow patterns in rooms with overhead mixing ventilation. 


\section{Introduction}

In indoor spaces people are constantly exposed to different pollutants present in the air. Airborne particles (also known as aerosol particles) are a major exposure concern due to their effects on human health. They can penetrate into the respiratory system and cause inflammatory effects. ${ }^{1,2}$ Particles with biological origins, such as bacteria and fungi, can activate allergic alveolitis and allergic asthma symptoms among occupants. ${ }^{3}$ Additionally, particles expelled (i.e. droplets) by people can carry pathogens and cause the transmission of infectious diseases to other occupants. ${ }^{4-5}$ Therefore, it is vital to have a good understanding of the spread of indoor aerosol particles, especially when they are released in occupied spaces. The most important reason that indoor environments are ventilated is to provide occupants with clean air for breathing. Many studies have shown that the effect of airflow distribution on personal exposure to indoor air pollutants varies with regards to the air distribution method used. ${ }^{5,7-13}$ Full-scale experiments and computational fluid dynamics (CFD) predictions are among the most popular methods used today to help understand the air pollution distribution in ventilated rooms. ${ }^{14,15}$

CFD modelling has become a powerful tool for studying indoor particle dispersion and spatial distribution ${ }^{13,16}$ Although CFD provides highly time- and space-resolved simulations, there are uncertainties and errors associated with the CFD boundary conditions and numerical schemes. ${ }^{17,18}$ Therefore, it is essential that the numerical simulations are validated with data obtained from experimental measurements. Full-scale experiments are valuable because they include actual thermo-fluid conditions, which allow studies to be performed at close to real conditions. A number of experimental studies relied only on tracer gas measurements to simulate the behaviour of both gaseous and particle indoor-emitted pollutants. For instance, tracer gases such as $\mathrm{N}_{2} \mathrm{O}$ and $\mathrm{CO}_{2}$ have been used to mimic the movement of infectious aerosol droplets emitted by air exhaled from a 
breathing thermal manikin in simulated hospital wards. ${ }^{7,8,19}$ However, particles are larger and heavier than gas molecules, and thus behave differently.

There are several differences between the behaviour of tracer gas and aerosol particles. The key difference is observed when they approach a surface; the tracer gas molecule reflects from the surface, whereas the aerosol particle attaches to the surface via an adhesive force. Moreover, the probability of particle deposition on a surface depends strongly on particle size. Ultrafine particles, up to diameters of a couple hundred nanometers, exhibit Brownian motion and deposit on all surfaces by diffusion; the smaller the particle the more intense the diffusional deposition is observed. Particles larger than several hundred nanometers in diameter exhibit non-negligible mass and inertia. They can be deposited either by gravitational settling at longer residence times on upward-facing surfaces or by inertial impaction at higher Stokes numbers on surfaces facing their original direction of motion. The larger the particles, the higher are the observed deposition rates. Particles in the middle size range, say between $200 \mathrm{~nm}$ to $1 \mu \mathrm{m}$, are only weakly influenced by the above-mentioned mechanisms and their deposition rates minimal.

Tang et al. ${ }^{15}$ reported in their review article that airborne particles (particularly exhaled droplet nuclei) smaller than 5 - $10 \mu \mathrm{m}$ can be simulated with tracer gas, since they often stay suspended in the air for long time. The study suggested that the particles will follow the air stream. However, only a few studies have conducted direct comparisons of tracer gas and particle behaviour in ventilated rooms. Zhang et al. ${ }^{16}$ made a direct comparison of the distribution of $\mathrm{SF}_{6}$ tracer gas and $0.7 \mu \mathrm{m}$ particles in an air-conditioned full-scale airliner cabin mock-up. They found that the distribution of the two simulated pollutants within the cabin was similar. However, they also concluded that the dispersion characteristics of micron-sized particles can still be different from that of a gas despite their general similarity. A study by Noakes et al. ${ }^{20}$, simulating a hospital isolation 
room with mixing air distribution (10 air changes per hour $(\mathrm{ACH})$ ), showed good agreement between the behaviour of $\mathrm{N}_{2} \mathrm{O}$ tracer gas and $3-5 \mu \mathrm{m}$ particles, both of which were released from a heated cylinder (resembling a patient in bed). Another related study by Beato-Arribas et al. ${ }^{21}$ concluded that $\mathrm{CO}_{2}$ tracer gas and aerosolised Bacilus Subtilus bacteria are comparable in their distribution in a single isolation hospital mock-up ventilated at $12 \mathrm{ACH}$. However, measurements of the pollutant concentrations at the breathing zone of a simulated person with realistic body geometry and skin temperature distribution were not performed in these studies. The complex human body shape and the buoyancy flows generated from the body are important for transport of pollution at the vicinity of the body, exposure, and air distribution in spaces. ${ }^{22,23}$

It is well-documented that the free convection flow $(\mathrm{FCF})$ around the human body adds to the complexity of a room's airflows interactions and occupants' exposure to pollutants. ${ }^{12,24-26}$ Licina et al. $^{24,25}$ studied the importance of FCF around a sitting person and its impact on the transport of gaseous and particle pollutants towards the breathing zone. However, the exposure to particles and tracer gas was studied in different set-ups and thus cannot be directly compared. Rim and Novoselac ${ }^{12}$ investigated the concentration distribution of particulate and gaseous pollutants in the vicinity of a human body at the same time. They considered the effects of the source position and the overall airflow patterns on the inhalation exposure to the airborne pollutants. These studies provide valuable information on the relationship between air distribution patterns in rooms and the transport of gaseous and particle pollutants. However, they did not provide information on how separate parameters, such as air change rate and increase of surface area by objects in rooms (furniture, etc.), may affect the deposition of particles and, therefore, the relationship between the distribution of gas and aerosol particles in the room. Such information is especially important when studies aim to evaluate the personal exposure to airborne particles in ventilated spaces using only tracer gas. 
Conducting experiments with particles is generally much more challenging than experiments with tracer gases. Due to the particles' complex nature and highly variable sizes, it is not easy to find and select available measuring techniques. ${ }^{27}$ The advantages of using only tracer gas in exposure measurements are the easy and inexpensive setup, possibility of sampling at many locations, and the relatively simple processing of the measured data. On the other hand, the gas cannot be used as a complex substitute for particles of all sizes due to the different physical forces acting on them. Moreover, particles have various morphologies and shapes, making the simplification of utilizing tracer gas as surrogate even more difficult.

The main objective of this study was to verify the use of tracer gas as a relatively accurate means of identifying exposure to different well-defined indoor aerosol particle sizes. It was examined the relationship between gas and particles dispersion in a room with overhead mixing air distribution. An important aim of this study was to identify the influence of factors, such as air change rate, the surface area inside the room, and the FCF around a sitting person (heated thermal manikin), on the distribution of monodispersed aerosol particles and tracer gas. This paper also investigated the effects of the interaction between the FCF generated by a lying person in bed and local exhaust airflow on the dispersion of particles and tracer gas released close to a body.

\section{Methods}

\section{Experimental set-up and design}

The experiments were performed in a test room of $2.6 \mathrm{~m}$ (height) x $4.7 \mathrm{~m}$ (length) x $1.66 \mathrm{~m}$ (width). The walls of the room were made of particleboard and were insulated with $0.06 \mathrm{~m}$ thick styrofoam plates. One of the walls was made from thick single-layer glazing. The room was carefully sealed prior to the experiments in order to avoid undefined infiltration. The room was air conditioned via mixing total volume air distribution. Outdoor air was supplied to the room through a two-way square ceiling diffuser with solid faceplate (the directions in which the two air jets were discharged 
by the supply diffuser are shown in Figure 1). The air supply diffuser was mounted in the centre of the ceiling. Just before entering the test room the supplied outdoor air was filtered by a highefficiency particulate (HEPA) filter, class H14, to assure particle-free air. The air was exhausted through a ceiling mounted circular diffuser $(\varnothing 200 \mathrm{~mm})$. The ventilation rate during the experiments was either 3.5 ACH or $7 \mathrm{ACH}$. Air supply diffusers with different sizes were used to achieve similar air jet pattern at 3.5 $\mathrm{ACH}$ and $7 \mathrm{ACH}$. The effective surface area of the diffusers was $0.0065 \mathrm{~m}^{2}$ at $3.5 \mathrm{ACH}$ and $0.015 \mathrm{~m}^{2}$ at $7 \mathrm{ACH}$. Detailed descriptions of the supply and exhaust diffusers are presented in Supporting Information section (Figures S1, S2; Tables S1, S2). The supply and exhaust airflow rates were kept constant using an electronic fan speed control and calibrated Iris orifice damper $(\varnothing 250)$. The room was under positive pressure during each experiment. Accuracy of the iris orifice damper was $\pm 5 \%$ of the actual pressure difference across the orifice damper.

The air temperature inside the room was controlled and kept at $23.2^{\circ} \mathrm{C} \pm 0.2^{\circ} \mathrm{C}$ during all experiments. The temperature around the room was kept at $23.2^{\circ} \mathrm{C} \pm 0.2^{\circ} \mathrm{C}$ as well. The relative humidity inside the room was recorded with a HOBO data logger (Model ONSET U12-013) and was in the range of $30 \%-38 \% \pm 2 \%$ throughout all experiments.

In this study five experimental scenarios were investigated in order to evaluate the effect of different parameters on the distribution of tracer gas and particles:

Empty room (Scenarios 1 and 2): scenarios 1 and 2 were performed in an empty room ventilated at 3.5 $\mathrm{ACH}$ and $7 \mathrm{ACH}$, respectively. The purpose was to determine the effect of different ventilation rates on the particle and gas concentration distributions. No heat sources were presented during these experiments, i.e. isothermal conditions. 
Furnished room with unheated manikin (Scenario 3): in this scenario a real-size unheated dressed thermal manikin was seated (on a computer chair) behind a table in the room. The distance between the abdomen of the manikin and the table was $0.1 \mathrm{~m}$. The ventilation rate in the room was $7 \mathrm{ACH}$. The purpose of this scenario was to quantify the particles and gas distribution in the presence of obstructions, such as furniture and a manikin. Obstructions increase the surface area that the air carrying the particles and gas was in contact with. There were no heat sources in the room, so isothermal conditions were studied.

Furnished room with heated manikin (Scenario 4): in this scenario the thermal manikin was switched on to represent realistic thermal conditions in an occupied indoor environment. The manikin was the only heat source in the room. The ventilation rate in the room was $7 \mathrm{ACH}$. The supply air temperature was set to $21.6{ }^{\circ} \mathrm{C} \pm 0.2{ }^{\circ} \mathrm{C}$ to keep the room $23{ }^{\circ} \mathrm{C}$.

In scenarios 3 and 4 the manikin was dressed with a tight long-sleeve shirt, trousers, underwear, socks, and shoes (the total clothing insulation was $0.48 \mathrm{clo}$ ). The thermal manikin had a realistic female body size and shape and consisted of 23 body segments. In scenario 4, each segment was individually controlled to maintain surface temperature equal to the skin temperature of an average person in a state of thermal comfort. The average total heat released from the manikin was $74.9 \mathrm{~W}$ $\pm 0.24 \mathrm{~W}$ (in scenario 4), which simulated the dry heat loss from a human body in a thermally comfortable state. The heat output from the manikin was measured using the MANIKIN software which controls the transfer of necessary power to each body part of the manikin. ${ }^{28}$ The height of the manikin in a sitting position was $1.3 \mathrm{~m}$. The layout of the room with the manikin is shown in Figure 1.

Single-bed hospital room (Scenario 5): In this scenario a patient hospital room was simulated. The test room was furnished with a bed with the thermal manikin lying on top (Figure 2). The mattress 
of the bed was covered with a cotton sheet. A localized exhaust system, ventilated mattress (VM), was placed on top of the regular mattress. The VM had an exhaust opening that was positioned below the gluteal region of the manikin. A full description of the VM can be found in Bivolarova et al. ${ }^{29}$ The manikin was dressed in short-sleeve hospital pyjamas (thermal insulation of 0.60 Clo). The head of the manikin was supported by a pillow. The measured average total heat released from the manikin was $73.2 \mathrm{~W} \pm 0.13 \mathrm{~W}$. The $\mathrm{ACH}$ in the room was 3.5 and the supply air temperature was $21.7^{\circ} \mathrm{C}$. The exhaust airflow rate of the ventilated mattress was adjusted to be $1.5 \mathrm{~L} / \mathrm{s}$. The exhausted air of the VM was taken out of the room through a separate exhaust system.

\section{Tracer gas and particle generation and measurement}

During the experiments for scenarios 1-4, particles of one of the three well-defined sizes $(0.07,0.7$, and $3.5 \mu \mathrm{m})$ and nitrous oxide $\left(\mathrm{N}_{2} \mathrm{O}\right)$ tracer gas were generated simultaneously at a constant rate from one location in the room, Figure 1. The three particle sizes were selected to represent particles from the ultrafine, fine, and coarse size ranges, each of which were influenced by different deposition mechanisms. Previous studies ${ }^{30,31}$ have shown that fine and coarse particles deposited on the surface of a mattress can be re-suspended by a person's movement in bed. In scenario 5 fine particles with $0.7 \mu \mathrm{m}$ size were released to compare their behavior with that of the tracer gas and at the same time to study the efficiency of the local exhaust ventilation when capturing particles. The pollution source for scenarios 1-4 was located $0.8 \mathrm{~m}$ behind the manikin with a height of $1 \mathrm{~m}$ (Figure 1). The pollution source for scenario 5 was located close to the gluteal region of the manikin (Figure 2b). The flows of the tracer gas and the particles were mixed in a T-piece connected to a plastic ball $(\varnothing 0.38 \mathrm{~m})$ with a number of small openings equally distributed across its surface. This provided low initial velocity of the tracer gas and particles released into the room. 
An AGK 2000 (Palas) aerosol generator connected to an electrostatic classifier (LACP made) was used to generate monodisperse ultrafine particles consisting of dry ammonium sulphate with mobility diameters (dp) of $0.07 \mu \mathrm{m}$. A MAG 3000 (Palas) aerosol generator was used to produce fine particles with aerodynamic diameters (da) of $0.7 \mu \mathrm{m}$ and coarse particles with $\mathrm{da}=3.5 \mu \mathrm{m}$. The fine and coarse particles consisted of a crystalline $\mathrm{NaCl}$ core covered with condensed DEHS (bis2(ethylhexyl)sebacate). The operating conditions of both aerosol generators were set to generate required sizes of aerosol particles according to aerosol spectrometers (with their measurement uncertainty $<3 \%$ in particle diameter). Both aerosol generators have in their specifications the geometric standard deviation, $\sigma_{\mathrm{g}}$, and these definitions agree well with measured size distributions from these generators. In the case of AGK 2000, during the experiments when producing the ultrafine particles with $0.07 \mu \mathrm{m}$ size in diameter, $\sigma_{\mathrm{g}}$ was 1.5 . In the case of MAG 3000, when we were producing $0.7 \mu \mathrm{m}$ and $3.5 \mu \mathrm{m}$ particles, $\sigma_{\mathrm{g}}$ was below 1.2.To suppress Brownian coagulation, experiments with ultrafine, fine, and coarse particles were conducted separately, the size distribution was kept as close as possible to the monodisperse fraction, and the tracer gas was always released with the particles. The $\mathrm{N}_{2} \mathrm{O}$ tracer gas was released from a compressed gas cylinder equipped with a gas rotameter (with accuracy of \pm 5 of full scale reading) to control the $\mathrm{N}_{2} \mathrm{O}$ flow rate. The $\mathrm{N}_{2} \mathrm{O}$ flow rate was kept at $0.15 \mathrm{~L} / \mathrm{min}$ across all experiments.

The tracer gas and particle concentrations were measured at three points in the room (during all scenarios 1-5) - at the exhaust air, at the centre of the room (1.7 m height), and either at the mouth of the manikin or, in the case of empty room, at a height of $1.12 \mathrm{~m}$ at the exact position of the manikin's mouth when it was installed. The particle number size distributions and total number concentration were measured with several types of aerosol spectrometers: Scanning Mobility Particle Sizer - SMPS 3936L (consisting of an Electrostatic Classifier EC 3080, Differential Mobility Analyzer DMA 3081, and Condensation Particle Counter CPC 3775), Optical Particle 
Sizer OPS 3330, Aerodynamic Particle Sizer APS 3321, and Condensation Particle Counter CPC 3022 (all TSI Inc., USA). The SMPS measured the ultrafine particle size distribution, whereas the APS and the three OPSs measured the size range of fine and coarse particles. The SMPS and APS were used as control measures to monitor the number size distribution of the ultrafine, fine, and coarse particles during the measurements and to verify the modal size of aerosol particles injected into the room. The SMPS was also used to monitor the total number concentration of ultrafine particles in the breathing zone of the manikin, while the CPC measured the total number concentration in the other two locations (centre of the room and exhaust), Figure 1b. In order to measure the ultrafine particle concentrations in the two locations an electrically actuated 2-way valve was used to automatically switch the sampling between the exhaust and the centre of the room (ambient air). The switching period of the valve was $5 \mathrm{~min}$. The sampling at the mouth of the manikin or at $1.12 \mathrm{~m}$ height (breathing zone) was performed without switching (i.e. the sampling at this position was continuous). The time resolution of the SMPS was 5 min ( 3 min scan, 1 min retrace of the voltage, $1 \mathrm{~min}$ waiting). The time resolution of the CPC was $1 \mathrm{sec}$. In the case of fine and coarse particles, APS was sampled together with one of the OPSs in the breathing zone of the manikin, while the other two OPSs were placed at the same spots as the sampling tubing for ultrafine particles (exhaust and centre of the room). The OPSs sampling time was 10 seconds, while the APS was sampled with a time resolution of 1 minute. The tracer gas concentration was measured simultaneously at all locations using an Innova 1303 multi-channel sampler and a photoacoustic Innova 1312 multi-gas monitor. The sampling time of the Innova gas monitor was 40 sec/channel. All instruments were placed outside the room except for the three OPSs. The sampling of the particles with the SMPS, CPC, and APS was performed through individual copper tubes of the same length (in order to avoid different losses in sampling tubings) connected to the instrument inlet. Co-location measurements using the three OPSs were performed and the linear correlation 
coefficients between the measurements were in the range of 0.9997-0.9999. The SMPS and CPC measure in practice the same concentrations (within maximum uncertainty of 10\%) at particle sizes around $0.07 \mu \mathrm{m}$ using the same dimensions of the sampling lines. The Innova gas monitor was also placed outside the room. The $\mathrm{N}_{2} \mathrm{O}$ gas was sampled through four plastic tubes with silicon lining $(\varnothing$ $4 \mathrm{~mm}$ ) connected to the channels of the gas monitor. The sampling points were the same as for the particles. It should be noted that the sampling tubes at the mouth of the thermal manikin were placed at the upper lip at a distance of $<0.01 \mathrm{~m}$ from the face. This way of sampling provides a representative measurement of the inhaled air concentration with a thermal manikin without breathing simulation. ${ }^{32}$

Measurements of particles and tracer gas concentrations were carried continuously from the start of the particle injection and the tracer gas until a steady-state was observed and a sufficient number of repeated measurements were obtained in order the variation in the tracer gas concentration to become $<10 \%$ (see Data analysis section). After a measurement was completed the concentration decay of aerosol particles and tracer gas were measured in most cases.

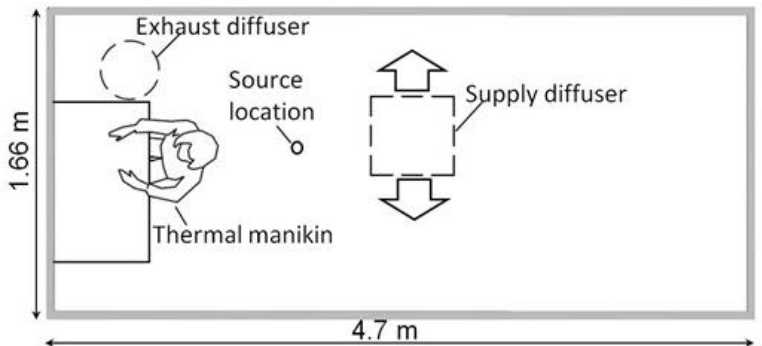

(a)

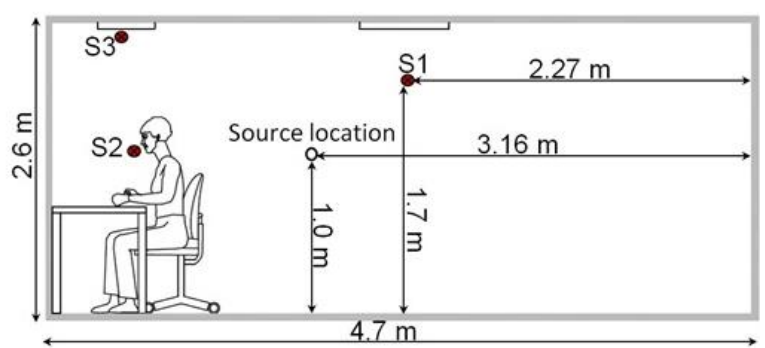

(b)

Figure 1. Top view (a) and side view (b) sketches of the room layout for scenarios 3 and 4 . Tracer gas and particle air sampling points are designated with S1, S2, and S3. 


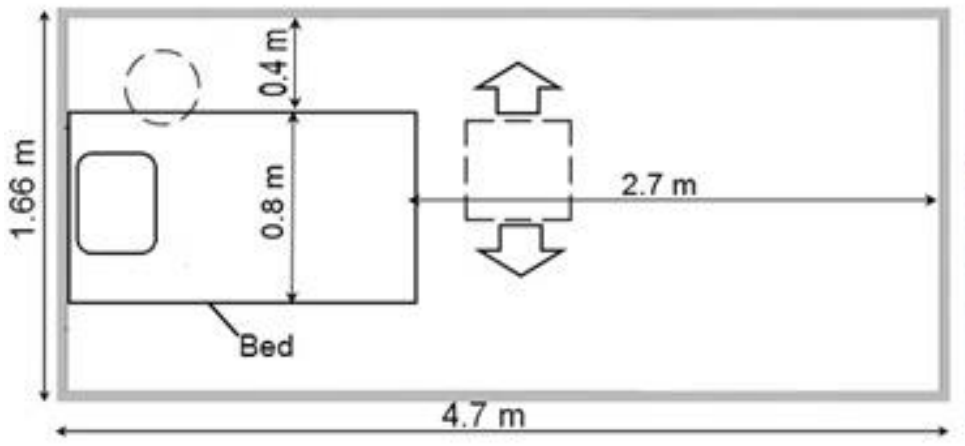

(a)

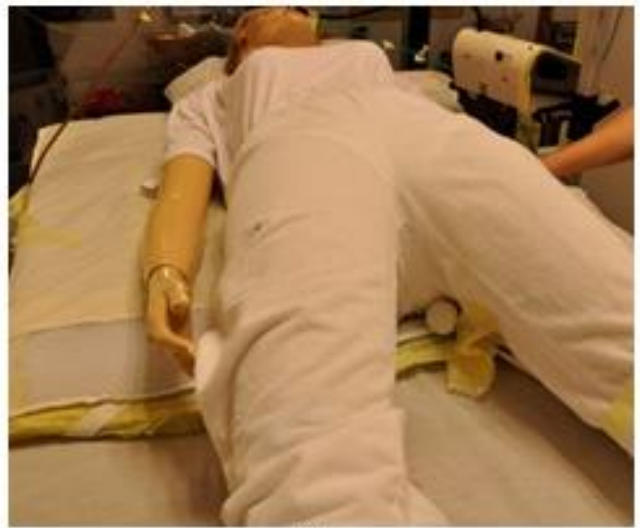

(b)

Figure 2. Experimental setup for scenario 5: (a) top view sketch of the room layout (b) pollution source close to the thermal manikin's gluteal region.

\section{Data analysis}

The data were analysed by estimating the average concentration of particles $\left(\# / \mathrm{cm}^{3}\right)$ and tracer gas (parts per million (ppm)) during the steady-state time period. The results were then normalized by the average concentration at the exhaust air. This type of normalization allowed comparison between all data sets across all the particles sizes. When the normalized concentration was less than " 1 " it meant that the concentration obtained at the measured location (breathing zone or centre of the room) was lower than the concentration at the exhaust (i.e. lower contaminant exposure). The variability (coefficient of variation $(\mathrm{CV})$ ) of the measurements of the particles and tracer gas is given in the results as error bars on the column chart. The $\mathrm{CV}$, calculated as the ratio of standard deviation to mean concentration obtained for each location, was less than $10 \%$ in most measurements and in the range of $11 \%-19 \%$ for only a few measurements. The standard deviation and the mean were calculated based on 50 samplings for the tracer gas, about 100 for the coarse and fine particles, and about 1400 for the ultrafine particles (sampled with the CPC using the 2-way valve). 20 samplings for the ultrafine particles were taken with the SMPS. All sample numbers were held for one steady-state only. 
Furthermore, the data were analysed in accordance with the ISO/IEC Guide ${ }^{33}$ for the expression of uncertainty. The absolute expanded uncertainty was estimated based on the bias and resolution of the instruments used to measure the aerosol particles and tracer gas concentrations as well as the reproducibility (standard deviation) of the measured concentrations. All uncertainties estimated based on the measured particle concentrations were $10 \%$ of the mean value for all particle instruments. All uncertainties of the tracer gas concentration measurements were calculated to be $5 \%$ of the mean. The absolute expanded uncertainties are reported at a $95 \%$ confidence interval with a coverage factor of 2 .The measured concentrations $\left(\mathrm{C}_{\mathrm{i}, \mathrm{t} n}\right)$ during scenario five were also normalized to the tracer gas and particle concentrations measured at time $t_{0}=0 \mathrm{~s}$ at the manikin's mouth and centre of the room $\left(\mathrm{C}_{\mathrm{i}, \mathrm{t} t}\right)$. The normalized concentrations $\left(\mathrm{C}_{\mathrm{i}, \mathrm{tn}_{\mathrm{n}}} / \mathrm{C}_{\mathrm{i}, \mathrm{t} 0}\right)$ for each sampling location were calculated by the following equation:

$\mathrm{C}_{\text {norm }}=\mathrm{C}_{\mathrm{i}, \mathrm{tn}} / \mathrm{C}_{\mathrm{i}, \mathrm{t} 0}$

where $\mathrm{C}_{\mathrm{i}, \mathrm{tn}}$ is the measured tracer gas or particle concentration at time $\mathrm{t}_{\mathrm{n}}$ and $\mathrm{C}_{\mathrm{i}, \mathrm{t}}$ is the measured gas or particle concentration at time $\mathrm{t}_{0}$.

Further analyses were performed on the concentration decay measurements in scenarios 1-4 in order to estimate the overall loss rates of aerosol particles of different sizes. Overall particle loss rate $\left(\lambda^{*}\right)$ includes the deposition rate of aerosol particles $(\beta)$ and air change rate $(\lambda)$ :

$\lambda^{*}=\lambda+\beta$

The overall particle loss rate can be derived from a simple mass balance equation ${ }^{34}$ describing the change in concentration of aerosol particles in an indoor environment:

$V \cdot \frac{d C_{i}}{d t}=V \cdot \lambda \cdot\left(P \cdot C_{o}-C_{i}\right)+Q-S$

where $V$ is the volume of the room , $C_{i}$ and $C_{o}$ are the concentrations of aerosol particles indoors and outdoors, $t$ is time, $\lambda$ is the air change rate, $P$ is the penetration factor, $Q$ represents possible 
particles sources. Parameter $S$ represents total sink strength of aerosol particles, including deposition, measured in number of particles removed from the volume $V$ per unit time. If we neglect coagulation of particles and their transformation due to condensation/evaporation and chemical reaction, the sink strength $S$ can be simplified to $S=C_{i} V \beta$, where $\beta$ is the deposition rate in the room comprising all deposition mechanisms and all surfaces.

Equation (3) can be simplified assuming that: 1) there is no source of aerosol particles in the room; 2) there is no resuspension of deposited aerosol particles; 3) particle coagulation can be neglected, 4) the initial aerosol particles concentration $C_{i}$ is equal to the initial condition $C_{i}(0)=C_{0}$ in order to obtain (after solving the differential equation) the equation describing the loss of aerosol particles: $C_{i}(t)=C_{\infty}+\left(C_{0}-C_{\infty}\right) \cdot e^{-\lambda^{*} \cdot t}$

where $C_{i}(t)$ represents concentration of aerosol particles of a given size indoors at time $t, C_{0}$ is the concentration of aerosol particles when the particle generation was stopped, $C_{\infty}$ is the concentration of aerosol particles in a steady-state (i.e. background aerosol particles concentration) and $\lambda^{*}$ is the overall particle loss rate.

The above mentioned assumptions were fulfilled during the measurements: 1) after the particle generation was finished there was no other source of aerosol particles; 2) the room air velocities were too low to be able to cause any measurable resuspension of deposited particles; 3 ) generated particles of all sizes were close to monodisperse distribution (with a geometric standard deviation below 1.2), and concentrations were relatively low, so Brownian coagulation could be neglected; 4) the particle concentration after the generation stopped was taken as the initial concentration at time 0. 
The experimental curves measured at the three locations for the three particle sizes and the scenarios 1-4 were fitted with the model using a MATLAB code utilizing the constrained NelderMead Simplex method ${ }^{35}$ in the code procedure. The method is used to find such parameters of the model equation that minimize the sum of squares of residuals between theoretical prediction and experimental data.

\section{Results}

\section{Overall particle loss rate for scenarios $1-4$}

Figure 3 shows particle overall loss rates obtained using the fitting of the simplified solution of mass balance model to experimental data by the procedure described above. It has to be noted that the mass balance model assumes ideal mixing in the space (homogeneous concentration). As will be shown later, this assumption was not fulfilled in all studied scenarios. Nevertheless, in the case of point measurements this method can be used assuming sufficient local mixing in the vicinity of the sampling point. Also, the overall particle loss rates are presented here instead of deposition rates. The deposition rates can be calculated by subtracting the air change rate from the overall particle loss rate assuming constant air change rate. The local air change rate in the sampling points was not measured and therefore it was not used for the calculation of the deposition rates. Moreover, the SMPS total concentration (breathing zone position) is burdened with higher uncertainty than CPC (centre of the room and exhaust position). These deviations may come from the higher charge on the generated aerosol particles (from the nebulizer) following incomplete particle charge neutralization (not reaching Boltzmann charge equilibria), which can result in under- or overestimation of particle concentrations in measured size bins (depending on the prevailing charge polarity). Nevertheless, keeping these limitations in mind, the SMPS data still represent valid information about aerosol particle concentration and its time evolution in the given point. 
Generally, it can be stated that in the scenarios $1-4$ the fine particles $(0.7 \mu \mathrm{m})$ reached the lowest values of overall particle loss rate, meaning that these particles should have had the most similar behaviour to the tracer gas. In other words, these particles were the least influenced by main deposition mechanisms (Brownian motion or gravitational settling). Figures 3A and 3B show that the particle loss was enhanced when the air change rate in the room was increased from 3.5 to 7 $\mathrm{ACH}$. The other general feature observed from the overall particle loss rate curves was that the lowest particle loss rates were obtained at centre of the room and were the highest in the breathing zone of the manikin (except for the fine and coarse particles with the heated manikin). This can be explained by non-ideal mixing in the room, which decreased the overall particle loss rates in the centre of the room and increased it in the breathing zone. The overall breathing zone particle loss rates were also increased by the presence of the manikin. The effect of increased deposition surface area (manikin, table, and chair) was more pronounced for ultrafine particles $(0.07 \mu \mathrm{m})$ than for coarse particles $(3.5 \mu \mathrm{m})$. These results can be explained by the fact that ultrafine particles are able to deposit on all the available surfaces due to Brownian diffusion. By contrast, coarse particles deposit by gravitational settling and settle mostly on upward facing surfaces - represented only by the table and manikin's cross-sections. On the other hand, the heating of the manikin decreased the values of overall particle loss rate substantially for fine and coarse particles at the breathing zone of the manikin. This effect could have been caused by the FCF around the manikin body, which narrows the boundary layer around the manikin. In addition, the non-ideal surface of manikin's clothing causes turbulence. The combined effect of these two factors can be enhancing deposition onto the manikin's surface. Therefore it can lower the initial concentration at the sampling point at the breathing zone. 


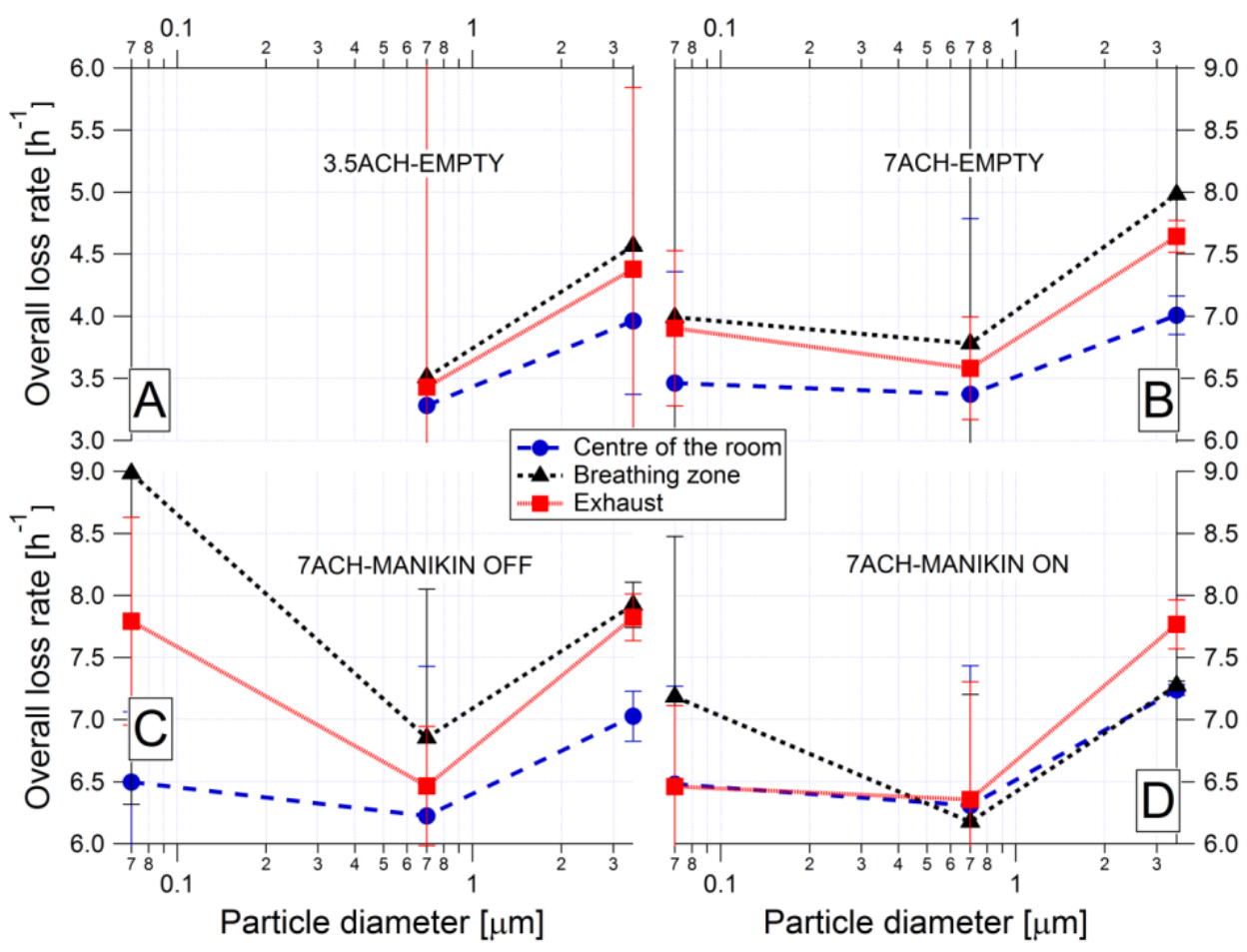

Figure 3. Aerosol particle overall loss rates calculated for different positions and particle sizes for different scenarios: A) $3.5 \mathrm{ACH}$ in an empty room, B) $7 \mathrm{ACH}$ in an empty room, C) $7 \mathrm{ACH}$, manikin heating OFF, D) $7 \mathrm{ACH}$, manikin heating ON. Points represent values determined by fitting the model equation. The error bars represent the values of root mean square error (RMSE), which corresponds to differences between model and the measured data. The connecting lines do not have any physical meaning and were added just to lead the readers' eye in order to easier recognize points which belong to the same scenario..

\section{Distribution of tracer gas and particles under steady-state conditions (scenarios 1-4)}

Figure 4 presents the normalized concentrations of the tracer gas and particles measured at the breathing zone and at the centre of the room during the first four experimental scenarios under steady-state conditions. The results in the figure indicate that there was a non-uniform concentration pattern in the room during each scenario. It can be seen that both tracer gas and particles' transport behaviour resulted in lower normalized concentrations at the centre of the room than at the breathing zone. Results for the ultrafine particles measured at the breathing zone are missing in 
Figure 4A due to instrument failure during these measurements. In Figure 4A the results show that the $\mathrm{N}_{2} \mathrm{O}$ tracer gas, fine $(0.7 \mu \mathrm{m})$ particles, and coarse $(3.5 \mu \mathrm{m})$ particles followed identical patterns at both measuring points with only 2 - $9 \%$ difference between the normalized concentrations. On the other hand, it is apparent that the concentration distribution of ultrafine $(0.07 \mu \mathrm{m})$ particles was quite different at the centre of the room than the $\mathrm{N}_{2} \mathrm{O}$ gas and the other particle sizes. This difference may be because more of the $0.07 \mu \mathrm{m}$ particles already deposited before being exhausted from the room due to diffusion compared to the tracer gas and the other particle sizes. As a result, the measured particle number concentration of the ultrafine particles was lower at the exhaust than at the centre of the room and therefore the normalized concentration of these particles was the highest in Figure 4A.

In order to find the impact of the ventilation rate on the gas and particle concentration distribution, the $\mathrm{ACH}$ in the empty room was increased from 3.5 $\mathrm{ACH}$ to $7 \mathrm{ACH}$. The results are presented in Figure 4B. In contrast to the experiment at $3.5 \mathrm{ACH}$, it can be seen that at $7 \mathrm{ACH}$ the ultrafine particle concentration pattern at the centre of the room was similar to the behaviour of the gas. The results in Figure 4B also show that in both measuring points there were no large differences between the $3.5 \mu \mathrm{m}$ and $0.7 \mu \mathrm{m}$ particle concentration distributions and the concentration pattern of the gas. These results suggest that the ventilation rate is important for comparing the behaviour of the ultrafine particles with tracer gas, whereas for coarse and fine particles it does not have big effect in the studied range. It should be noted that the concentration of the $0.07 \mu \mathrm{m}$ particles at the breathing zone in the empty room was slightly higher than the gas distribution and the other particle sizes.

In mechanically ventilated spaces airborne particles tend to deposit on indoor surfaces without being exhausted from the space. A table and an unheated dressed manikin sitting on a computer 
chair were added to the room in order to determine if the particle concentration distribution would be affected. The results from this experiment are shown in Figure 4C. Overall, the normalized concentration distribution of all particles, as well as the tracer gas, was not changed by the additional surfaces in the room. By comparing the results shown in Figure $4 \mathrm{~B}$ and $4 \mathrm{C}$, it is observed a tendency that the particles' normalized values obtained at the breathing zone decrease when the furniture and the manikin were added to the room. Since mixing air distribution does not always assure totally mixed flow, it should always be expected a change in the normalized values when the flow pattern in the room is changed by other air speed or geometry, etc. The gas and particle concentration at the centre of the room remained the same (Figure 4C), as was the case of the empty room at $7 \mathrm{ACH}$ (Figure 4B).

The results obtained from the experiment with the heated manikin are shown in Figure 4D. In Figure 4D the concentration distributions of the $\mathrm{N}_{2} \mathrm{O}$ gas and the particles show similar behaviour as can be observed in Figures $4 \mathrm{~B}$ and $4 \mathrm{C}$. In contrast to the results in Figure 4B and 4C, the difference between the normalized concentration of the gas and the $0.07 \mu \mathrm{m}$ particles in the breathing zone of the heated manikin was the smallest. When comparing Figures 4C and 4D it is clear that the normalized concentration of $0.07 \mu \mathrm{m}$ particles at the breathing zone decreased by about $18 \%$ when there was FCF around the manikin. The FCF around the manikin did not prevent the smallest particles to move around the manikin. In fact, the FCF made the boundary layer thinner and, in combination with the non-ideal surface of the manikin's clothing caused some turbulence. As a result the ultrafine particles deposited more on the manikin's surface due to diffusional deposition (both Brownian and turbulent). Figure 4D also shows that the normalized values of the gas and the three sizes of particles at the centre of the room were closer to ' 1 ' than the other two experimental scenarios at $7 \mathrm{ACH}$. The results suggest that the presence of the free convection flow 
that transformed to a thermal plume above the manikin's head enhanced the mixing of the air in the room.

Strong linear correlation was found between the mean concentration values of all different size particles and $\mathrm{N}_{2} \mathrm{O}$ tracer gas. The linear relationship $\left(\mathrm{r}^{2}\right)$ between the tracer gas and the particle sizes $3.5 \mu \mathrm{m}$ and $0.7 \mu \mathrm{m}$ was above 0.9 . The $\mathrm{r}^{2}$ coefficients of determination between the ultrafine particles and the gas for the different scenarios (1-4) were in the range of 0.7-0.85.

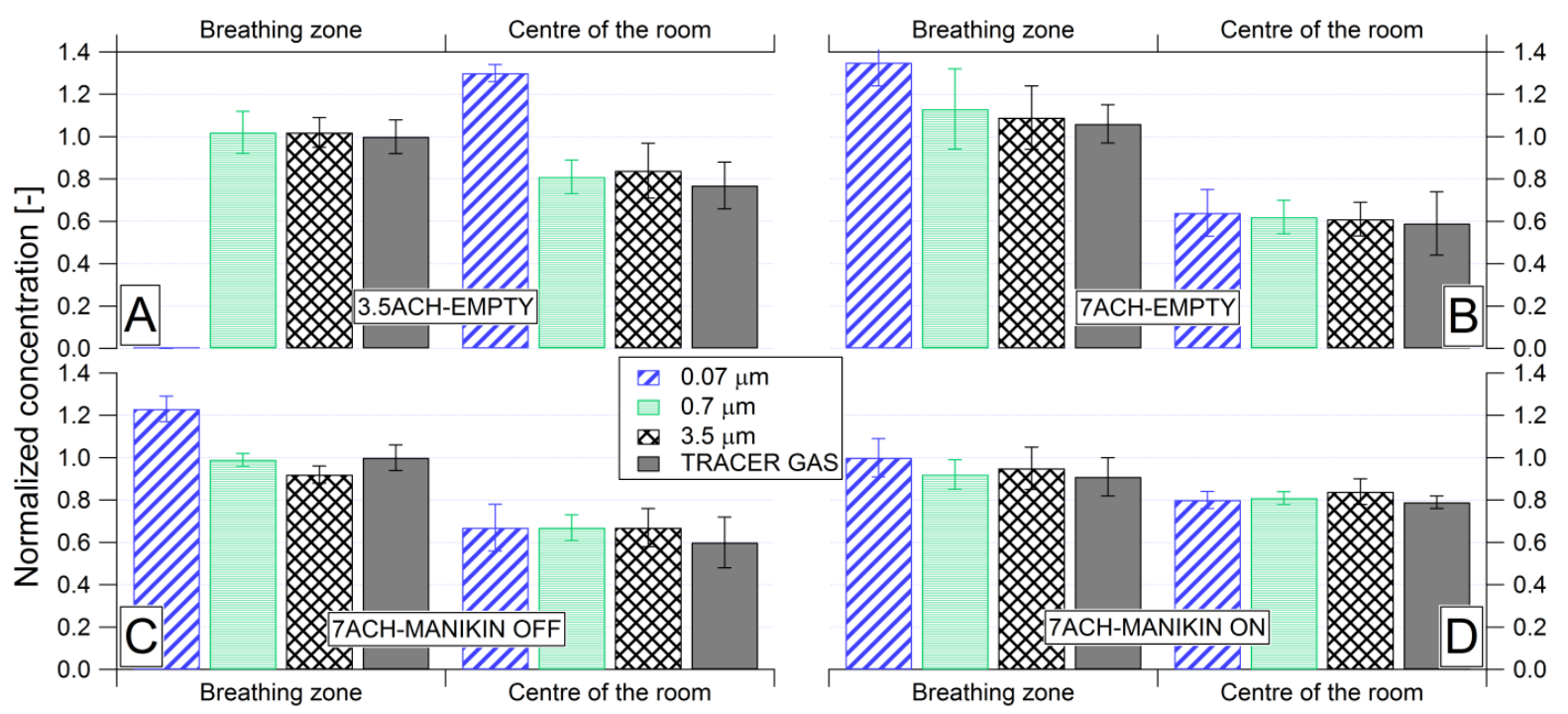

Figure 4. Comparison of normalized concentrations across $\mathrm{N}_{2} \mathrm{O}$ tracer gas and different-sized particles for the first four scenarios: A) $3.5 \mathrm{ACH}$ in empty room, B) $7 \mathrm{ACH}$ in empty room, C) 7 $\mathrm{ACH}$, manikin heating $\mathrm{OFF}$, and D) $7 \mathrm{ACH}$, manikin heating $\mathrm{ON}$.

\section{Scenario 5: single-bed hospital room}

Figure 5 illustrates the variation of the normalized concentrations of the tracer gas and $0.7 \mu \mathrm{m}$ particles measured at the mouth, centre of the room, and the exhaust as a function of time. The ventilated mattress $(\mathrm{VM})$ worked from the start of the gas and particles generation i.e. at time $0 \mathrm{~s}$. The generation of the pollutants was constant during the whole measuring period shown in Figure 5. It can be seen that the concentration curves for the gas and particles are identical. The normalized 
steady-state data showed that there was only $5 \%$ difference between the gas and the fine particles normalized (by the average concentration at the exhaust) average values at the breathing zone and $2 \%$ difference at the centre of the room. From the data in Figure 5, it can also be seen that the VM had high capturing efficiency, reducing the contaminant concentrations by about $90 \%$ after reaching steady-state $\mathrm{N}_{2} \mathrm{O}$ gas and particle concentrations.

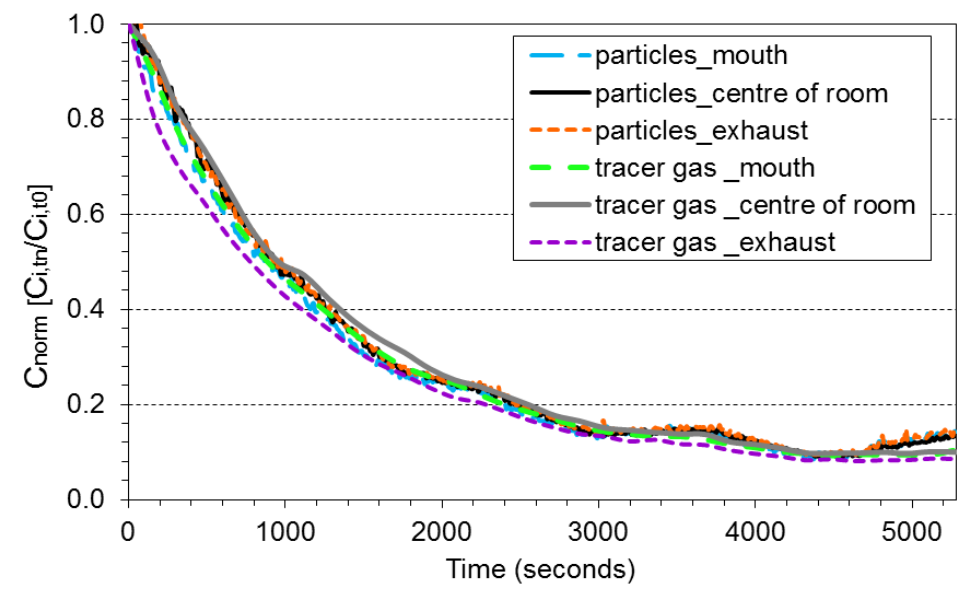

Figure 5. Comparison of the normalized $0.7 \mu \mathrm{m}$ particle concentration with tracer gas normalized concentration based on release close to the manikin's body, and effect of local exhaust ventilation.

\section{Discussion}

\section{Overall particle loss rate}

The overall loss of the particles due to deposition was affected by the different controlled parameters. Our results show that the increased surface (presence of manikin, table, and chair) mainly influenced ultrafine particles $(0.07 \mu \mathrm{m})$ deposited on all surfaces as opposed to coarse particles deposited dominantly on upward facing surfaces. This agreed with the finding reported by Thatcher et al. ${ }^{36}$ that large particles are not strongly influenced by increases in vertical and downward facing surface area. On the contrary, submicron particles are more strongly affected, since they deposit effectively to surfaces of all orientations. In the current study it was also found that at the higher airflow rate the loss rate of the particles of all sizes increased. These results are 
consistent with other research which found the same effect of increasing the room airflow rate on the particles deposition. ${ }^{36,37}$ In general, aerosol particle deposition indoors is important because it decreases the air particle concentration and thus the occupants' exposure. It is interesting to note that in this study the convective flow created a "protective" boundary layer around the heated manikin surface and decreased the overall particle loss rate in the breathing zone. Thus the interaction of the background flow and the free convection flow are important for the transport of and exposure to aerosol particles.

\section{Impact of ventilation rate}

The airflow pattern within a room can have a considerable effect on the transport of airborne normalized pollutants. This study shows that there was a concentration gradient in the room (when steady-state was reached) for the gas and particles at both $3.5 \mathrm{ACH}$ and $7 \mathrm{ACH}$. Yet, the normalized concentration of the $\mathrm{N}_{2} \mathrm{O}$ tracer gas, the fine particles, and the coarse particles followed similar distributions at the measured points in the room during scenarios 1-4. This indicates that airborne particles behave like tracer gas for air change rates exceeding 3.5 ACH However, it was also found that the transport behavior of ultrafine particles is influenced by the ventilation rate more than fine and coarse particles. It is known that Brownian diffusion is an important deposition mechanism for ultrafine particles. ${ }^{38}$ In the present study at the lower ventilation rate the Brownian diffusion seems to be dominant over the airflow pattern in the room when compared to the higher ventilation rate. The Brownian motion is moving the particles in all directions with the same probability unless there is another driving force directing the particles. Whenever the particle gets close to the surface it has to overcome the boundary layer. The deposition is thus also influenced by the thickness of the boundary layer. In the case of the Brownian diffusion, the wall acts as a particle sink causing concentration gradient across the boundary layer and therefore results in diffusional flux of particles towards the wall. However, the magnitude of this effect needs to be verified by direct measurements 
of particle deposition on surfaces and visualizating flow patterns or modelling of the flow field by CFD tools. Nevertheless, it is possible to hypothesize that ultrafine particles will not act as tracer gas in a room where the air change rate (ACR) is low (in our case $3.5 \mathrm{ACH}$ or lower). In contrast, at $7 \mathrm{ACH}$ and with an empty room the distribution of $0.07 \mu \mathrm{m}$ particles was similar to that of the other particles and gas, suggesting that the particles followed the airflow pattern in the room better than 3.5 $\mathrm{ACH}$. It is worthwhile to note that the air change rate has a huge influence on the absolute concentrations (double flow rate, half concentration). In the current study the used normalization of the data is to be able to compare gas concentrations with particle concentrations.

\section{Comparison with other studies}

The findings in this study are in agreement with the findings of previous studies that showed tracer gas can be used to evaluate the distribution of aerosol particles in ventilated rooms. ${ }^{12,16,20}$ The concentration patterns of tracer gas measured at the mouth of the heated manikin and the centre of the room appeared to be comparable to that of all the studied particle sizes. These results are in agreement with Rim and Novoselac's findings ${ }^{12}$, which showed that highly mixed airflow (4.5 $\mathrm{ACH})$ in a room creates relatively uniform and comparable gas and particles concentration patterns in the vicinity of a thermal manikin. The study by Rim and Novoselac ${ }^{12}$ was carried out with monodispersed particles with aerodynamic diameters of $0.03,0.77$, and $3.2 \mu \mathrm{m}$ and the pollution source was located either $1 \mathrm{~m}$ above the floor (similar to the pollution source in this study) or near the occupant's feet. The measurements in this study were carried out using SMPS and APS instruments. These instruments have high size resolution that allowed us to monitor the number size distribution of the ultrafine, fine, and coarse particles and to justify with high accuracy the modal size of the injected aerosol particles.

\section{Impact of interaction of airflows and objects}


An important finding was that the increase in the contact surface area of room objects with room air by the addition of a table and seated unheated manikin did not change the similarity of the distribution pattern of the $0.07 \mu \mathrm{m}, 0.7 \mu \mathrm{m}$, and $3.5 \mu \mathrm{m}$ particles to that of the tracer gas, Figure $4 \mathrm{C}$. Despite these results, it should be noted that the additional surfaces were relatively small in comparison to the surface of the empty room. That is why no significant change was observed in the normalized concentration distribution.

The interaction between the FCF generated around the body of the heated manikin with the background room changed the air distribution in the room and resulted in a more homogeneous environment, Figure 4D. Nonetheless, it did not influence the similar transport pattern of the particles and the gas. On the contrary, it seems that when there is FCF around the manikin the difference in the normalized concentration distributions between the $0.07 \mu \mathrm{m}$ particles and the tracer gas at the breathing zone decreases. This finding suggests that tracer gas can be used as a measure of occupants' exposure even to ultrafine particles.

The above results confirm that the convective boundary layer is important for personal exposure as well as the level of mixing between the supply air and room air. ${ }^{12,24-26}$ Depending on the source location and background pollution distribution the free convection boundary layer may increase exposure or reduce it. It also may not affect the exposure (i.e. complete mixing). Since the room air distribution is difficult to control, an advanced air distribution supplying clean air to the breathing zone is recommendable. ${ }^{39}$ Localized exhaust methods can also be used to remove particles from active indoor heat sources such as the human body and exhaled air. ${ }^{8,29,40}$

\section{Single-bed hospital room}

The results from this scenario clarified to what extent measurement of tracer gas distribution can be used to predict $0.7 \mu \mathrm{m}$ particle transport when released or re-suspended from a person's body or 
from a mattress while a person is resting in bed. The results show that the particles behave exactly the same as the tracer gas when a person is in a supine position and his/her FCF is disturbed by local exhaust airflow. To develop a full picture of the tracer gas and particle behaviour when they are released from a lying person, additional studies will be needed that include measurements of other particle sizes and do not include a local exhaust in the bed.

\section{Implication of results}

The current results suggest that tracer gas can be used to assess the removal of particles (range: 0.07-3.5 $\mu \mathrm{m}$ ) to validate the performance of mixing air distribution in certain room layouts. Comparison of tracer gas and particle normalized concentrations measured at the mouth of the heated manikin also suggest that tracer gas can be used to predict potential personal exposure to $0.07 \mu \mathrm{m}, 0.7 \mu \mathrm{m}$, and $3.5 \mu \mathrm{m}$ particles. There are many disease-causing microorganisms that have similar particle sizes to the ones used in this study. For instance, most contagious bacteria have sizes within the fine range of $0.2-1 \mu \mathrm{m}$. Furthermore, airborne droplet nuclei (evaporated droplets generated by human respiratory activities) range from $1-5 \mu \mathrm{m} .{ }^{41}$ Curseu et al. ${ }^{41}$ also reported that spores of Aspergillus fumigatus have diameters of 2-3.5 $\mu \mathrm{m}$ and can exhibit similar behaviour in the air as droplet nuclei. Understanding the dynamic behavior of ultrafine particles is also of interest since there are health concerns associated with the inhalation exposure to abiotic ultrafine particles. It should be noted that the tracer gas concentration cannot be directly used to determine the health risk of such infectious pathogens, but it can give an indication for personal exposure to air contaminated with such pathogens.

Previous studies have demonstrated that a significant fraction of human-induced resuspension of particles from mattresses and bedding can be inhaled by sleeping occupant. ${ }^{30,31}$ The airflow interaction in the microenvironment of a person has a fundamental effect on their exposure to 
pollutants generated in the vicinity of the body. ${ }^{26}$ Hence, in order to improve a person's inhaled air quality, it is suggested that the microenvironment close to the human body is locally controlled. The present study shows that there is the possibility of testing local exhaust ventilation systems for their ability to remove fine aerosol particle contaminants using tracer gas.

\section{Study limitations}

These results raise the possibility of using tracer gas techniques to predict the distribution of aerosol particles in ventilated rooms with some limitations in regards to particle size. The findings in the study cannot be extrapolated to all particle sizes, especially for particles in the coarse-mode range larger than $3.5 \mu \mathrm{m}$. It is expected that the use of gaseous tracers to mimic the behavior of aerosol particles would progressively decrease as size increases in this range. The study did not take into account also other air distribution patterns, such as displacement air distribution or other positions of the supply and exhaust diffusers. The study is also restricted to processes taking place only in rooms without recirculation. The location and type of the source and occupants' activity may also have different effects on particle and gas dispersion. The current source location may produce better particle and gas comparisons in contrast, for example, if the source was located close to a surface such as the floor, for which particles deposition losses before mixing occurs would be more important. The lack of proper simulations of the occupant's breathing flow in this study might lead to some incorrect predictions, especially for coarse particles (as shown by Rim and Novoselac ${ }^{12}$ ). This needs to be further studied.

The tracer gas and particles concentrations were measured at only three points in the room due to not enough available particle counters. It is hard to draw a general conclusion about the use of tracer gas to simulate the aerosol particles behavior in all possible situations in practice. All conclusions are based on the variation in the measured values at the three sampling points in the room. Future 
studies on the current topic are therefore recommended and should include more measuring points as well as analysis of the decay rate of tracer gas and different particle sizes compared to local air change rate. Such analysis can provide better understanding if it is the particle deposition or just mixing patterns that lead to differences or similarities between observed gas and particle behavior.

Another restriction of the current study is that the effect of ACR was examined only in the case of an empty room. Future studies should also examine the impact of different ACRs on the gas and aerosol particles dispersion in a furnished room and the presence of heat sources.

\section{Conclusions}

This study focused on the comparison of the concentration dispersion of tracer gas and particles with different sizes in a full-scale test room. The effects of different parameters on the gas and the particles distribution were studied, including air change rate, change in the room surface area, and FCF around an occupant body. The results show that:

- Particles in the fine size range $(0.7 \mu \mathrm{m})$ are the least influenced by deposition mechanisms and thus should have the most similar behaviour to the tracer gas;

- The ventilation rate was important for comparing the behaviour of the ultrafine particles and tracer gas; for the $3.5 \mu \mathrm{m}$ and the $0.7 \mu \mathrm{m}$ particles the studied ventilation rates did not have a large effect;

- Increasing the room surface area did not influence the similarity of the $0.07 \mu \mathrm{m}, 0.7 \mu \mathrm{m}$, and 3.5 $\mu \mathrm{m}$ particle dispersal to that of the tracer gas;

- At the breathing zone of the seated heated manikin $\mathrm{N}_{2} \mathrm{O}$ gas emerged as a reliable predictor of the exposure to all tested different-sized particles. Furthermore, the results of this study suggest that tracer gas can be used to indicate the exposure of a person lying in bed to $0.7 \mu \mathrm{m}$ aerosol particles. 
More research is needed to provide data on rooms with different furniture layout, source location, thermal plumes generated by various heated objects, and occupant movement.

\section{Acknowledgement}

This work was supported by the European Union 7th framework program HEXACOMM FP7/20072013 under grant agreement No 315760.

\section{Supporting Information}

Additional Supporting Information may be found in the online version of this article:

Figure S1. a) Picture of the supply air diffuser, b) common dimensions of the two supply diffusers. Figure S2. a) Picture of the exhaust air diffuser, b) dimensions of the exhaust diffuser.

Table S1. Specific dimensions of the supply air diffusers.

Table S2. Specific dimensions of the exhaust air diffuser.

\section{Reference}

1.Koullapis PG, Kassinos SC, Bivolarova MP, Melikov AK. Particle deposition in a realistic geometry of the human conducting airways: Effects of inlet velocity profile, inhalation flowrate and electrostatic charge. J Biomech. 2016;49:2201-2212.

2.Long CM, Suh HH, Catalano PJ, Koutrakis P. Using time- and size-resolved particulate data to quantify indoor penetration and deposition behavior. Environ Sci Technol. 2001;35:2089-2099.

3. Burge H. Bioaerosols: prevalence and health effects in the indoor environment. J. Allergy Clin. Immunol. 1990; 86, 687-701. 4. Bolashikov ZD, Melikov AK. Methods for air cleaning and protection of building occupants from airborne pathogens. Build Environ. 2009;44:1378-1385.

5.Li Y, Leung GM, Tang JW, et al. Role of ventilation in airborne transmission of infectious agents in the built environment - a multidisciplinary systematic review. Indoor Air. 2007;17:218. 
6.Morawska L. Droplet fate in indoor environments, or can we prevent the spread of infection? Indoor Air. 2006;16:335-347.

7.Bjørn E and Nielsen PV. Dispersal of exhaled air and personal exposure in displacement ventilated room. Indoor Air. 2002;12:147-164.

8. Bolashikov ZD, Melikov AK, Kierat W, Popiolek Z, Brand M. Exposure of health care workers and occupants to coughed airborne pathogens in a double-bed hospital patient room with overhead mixing ventilation. Hvac\&R Research. 2012;18:602-615.

9. Cermak R, Melikov AK. Air quality and thermal comfort in an office with underfloor, mixing and displacement ventilation, International Journal of Ventilation. 2006;5, 323-332.

10. Nielsen PV, Buus M, Winther FV, Thilageswaran M, Ashrae. Contaminant Flow in the Microenvironment Between People Under Different Ventilation Conditions. Ashrae Transactions. 2008;114:632-638.

11. Olmedo I, Nielsen PV, de Adana MR, Jensen RL, Grzelecki P. Distribution of exhaled contaminants and personal exposure in a room using three different air distribution strategies. Indoor Air. 2012;22:64-76.

12. Rim D, Novoselac A. Transport of particulate and gaseous pollutants in the vicinity of a human body. Build Environ. 2009;44:1840-1849.

13. Zhao B, Zhang Y, Li XT, Yang XD, Huang DT. Comparison of indoor aerosol particle concentration and deposition in different ventilated rooms by numerical method. Build Environ. 2004;39:1-8.

14. Chen QY. Ventilation performance prediction for buildings: A method overview and recent applications. Build Environ. 2009;44:848-858. 
15. Tang JW, Noakes CJ, Nielsen PV, et al. Observing and quantifying airflows in the infection control of aerosol- and airborne-transmitted diseases: an overview of approaches. J Hosp Infect. 2011;77:213-222.

16. Zhang Z, Chen X, Mazumdar S, Zhang TF, Chen QY. Experimental and numerical investigation of airflow and contaminant transport in an airliner cabin mockup. Build Environ. 2009;44:85-94.

17. Sørensen DN, Nielsen PV. Quality control of computational fluid dynamics in indoor environments. Indoor Air. 2003;13:2-17.

18. Wang M, Lin CH, Chen QY. Advanced turbulence models for predicting particle transport in enclosed environments. Build Environ. 2012;47:40-49.

19. Qian H, Li Y, Nielsen PV, Hyldgaard CE, Wong TW, Chwang ATY. Dispersion of exhaled droplet nuclei in a two-bed hospital ward with three different ventilation systems. Indoor Air. 2006;16:111-128.

20. Noakes CJ, Fletcher LA, Sleigh PA, Booth WB, Beato-Arribas B, Tomlinson N. Comparison of tracer techniques for evaluating the behaviour of bioaerosols in hospital isolation rooms. Proceedings of Healthy Buildings. 2009; 9th international conference and exhibition, Syracuse, NY, USA. Paper \#504.

21. Beat-Arribas B, McDonagh A, Noakes CJ, Sleigh PA. Assessing the near-patient infection risk in isolation rooms. Proceedings of Healthy Buildings 2015, ISIAQ International Conference, Eindhoven, the Netherlands, May 18-20, paper \#537.

22. Melikov A. Breathing thermal manikins for indoor environment assessment: important characteristics and requirements. Eur J Appl Physiol. 2004;92:710-7 ${ }^{13}$.

23. Zukowska D, Melikov A, Popiolek Z. Impact of geometry of a sedentary occupant simulator on the generated thermal plume: Experimental investigation. Hvac\&R Research. 2012;18:795-811. 
24. Licina D, Melikov A, Pantelic J, Sekhar C, Tham KW. Human convection flow in spaces with and without ventilation: personal exposure to floor-released particles and cough-released droplets. Indoor Air. 2015;25:672-682.

25. Licina D, Melikov A, Sekhar C, Tham KW. Transport of gaseous pollutants by convective boundary layer around a human body. Sci Technol Built Environ. 2015;2:1175-1186.

26. Melikov AK. Human body micro-environment: The benefits of controlling airflow interaction. Build Environ. 2015;91:70-77.

27. Morawska L, Afshari A, Bae GN, et al. Indoor aerosols: from personal exposure to risk assessment. Indoor Air. 2013;23:462-487.

28. Manikin software for controlling a Thermal Manikin, www.manikin.com

29. Bivolarova MP, Melikov AK, Mizutani C, Kajiwara K, Bolashikov ZD. Bed-integrated local exhaust ventilation system combined with local air cleaning for improved IAQ in hospital patient rooms. Build Environ. 2016;100:10-18.

30. Boor BE, Spilak MP, Corsi RL, Novoselac A. Characterizing particle resuspension from mattresses: chamber study. Indoor Air. 2015;25(4):441-456.

31. Spilak MP, Boor BE, Novoselac A, Corsi RL. Impact of bedding arrangements, pillows, and blankets on particle resuspension in the sleep microenvironment. Build Environ. 2014;81:60-68.

32. Melikov AK, Kaczmarczyk J. Measurement and prediction of indoor air quality using a breathing thermal manikin. Indoor Air. 2007; 17: 50-9.

33. ISO/IEC Guide 98-3:2008. Uncertainty of measurements -- Part 3: Guide to the expression of uncertainty in measurement (GUM: 1995); 2008.

34. Smolík, J., Lazaridis, M., Moravec, P., Schwarz, J., Zaripov, S. K. , Ždímal, V. Indoor aerosol particle deposition in an empty office. Water, Air and Soil Pollution. 2005; 165:301312 
A comparison between tracer gas and aerosol particles

35. Lagarias JC, Reeds JA, Wright MH, Wright PE. Convergence properties of the Nelder-Mead simplex method in low dimensions. Siam J Optimiz. 1998;9:112-147.

36. Thatcher TL, Lai ACK, Moreno-Jackson R, Sextro RG, Nazaroff WW. Effects of room furnishings and air speed on particle deposition rates indoors. Atmos Environ. 2002;36:18111819.

37. Mosley RB, Greenwell DJ, Sparks LE, Guo Z, Tucker WG, Fortmann R, Whitfield C. Penetration of ambient fine particles into the indoor environmemnt. Aerosol Sci Technol. 2001;34:127-136.

38. Nazaroff WW. Indoor particle dynamics. Indoor Air. 2004; 14:175-183.

39. Melikov AK. Advanced air distribution: improving health and comfort while reducing energy use. Indoor Air. 2016;26:112-124.

40. Melikov AK, Dzhartov V. Advanced air distribution for minimizing airborne cross-infection in aircraft cabins. Hvac\&R Research. 2013;19:926-933.

41. Curseu D, Popa M, Sirbu D, Popa MS. Engineering Control of Airborne Disease Transmission in Health Care Facilities. IFMBE Proceedings.2009; 26:1-4. 